\title{
Estimativas de Rendimentos de Cortes Comerciais e de Tecidos de Suínos em Diferentes Pesos de Abate pela Técnica de Ultra-sonografia em Tempo Real ${ }^{1}$
}

\author{
Wilson Moreira Dutra Jr. ${ }^{2}$, Aloízio Soares Ferreira ${ }^{3}$, Jaime Urdapilleta Tarouco ${ }^{4}$, \\ Ricardo Frederico Euclydes ${ }^{3}$, Juarez Lopes Donzele ${ }^{3}$, Paulo Sávio Lopes ${ }^{3}$, \\ Leandro Lunardini Cardoso ${ }^{4}$
}

\begin{abstract}
RESUMO - Foram utilizadas 48 fêmeas suínas abatidas aos 50, 60, 70, 80, 90, 100, 110 e 120 kg para determinar os rendimentos de cortes comerciais e de carne magra na carcaça, visando-se estimar área de olho de lombo (AOL) e espessura de toucinho (ET), utilizandose a técnica de ultra-sonografia em tempo real. Foram tomadas medidas ultra-sônicas in vivo, para AOL e ET; nas carcaças quentes, utilizou-se equipamento óptico da marca Hennessy, a fim de estimar a ET e profundidade de músculo (PM). As equações para estimar a quantidade de músculo na carcaça obtiveram $R^{2}$ entre 0,97 e 0,99 , com desvio-padrão residual entre 0,27 e 0,73 . Os valores de $R^{2}$ para área de olho de lombo, por ultra-som e pela medida direta nas carcaças, foram de 0,97 e 0,98 , respectivamente, com desvio-padrão residual para as duas estimativas de 3,07 e 3,13. Os ajustes das equações para espessura de toucinho por ultra-som, espessura de toucinho óptico e espessura de toucinho medida diretamente na carcaça apresentaram $\mathrm{R}^{2}$ de 0,$99 ; 0,82$; e 0,86 , respectivamente, com desvio-padrão residual de 2,39; 3,13; e 2,91. As equações obtidas por regressões lineares e múltiplas, a partir dos dados da dissecação, ajustaram equações precisas para estimar rendimento de cortes comerciais e de carne magra nas carcaças de suínos entre 50 e $120 \mathrm{~kg}$ de peso corporal. A técnica de ultra-sonografia em tempo real é acurada para se estimarem a área de olho de lombo e a espessura de toucinho de suínos in vivo.
\end{abstract}

Palavras-chave: área de olho de lombo, cortes cárneos, equações simples e múltiplas, espessura de toucinho, rendimento de carne magra

\section{Estimate of Commercial Cuts Yield and Tissues of Swines in Different Slaughter Weights by the Real-Time Ultrasound Technology}

\begin{abstract}
Forty-eight female pigs slaughter at 50, 60, 70, 80, 90, 100, 110 and $120 \mathrm{~kg}$ were used to determine commercial cut and of lean meat yields in pork carcass, with a view of the Longissimus muscle area and backfat thickness estimation by using the realtime ultrasound technology. Live ultrasonic measurements were taken for Longissimus muscle area and for backfat thickness and measures in the hot carcass were made, using optical Henessy equipment, to estimate the backfat thickness and Longissimus muscle depth. The regression equations to estimate the amount of muscle in the carcass obtained a $R^{2}$ between 0.97 and 0.99 , with a residual standard deviation (RSD) between 0.27 and 0.73 . The $\mathrm{R}^{2}$ values for Longissimus muscle area obtained by ultrasound and for backfat thickness direct in the carcass, were 0.97 and 0.98 , respectively, with a RSD of 3.07 and 3.13. The adjustment of the regression equations for ultrasound backfat tickness, for optical backfat tickness and for directly carcass backfat tickness measurement, presented $\mathrm{R}^{2}$ of $0.99,0.82$, and 0.86 , respectively, with a RSD of 2.39,3.13, and 2.91. The fitted regression equations obtained by simple and multiple linear regressions from the dissection data set were precise to estimate commercial cuts and of lean meat of pork carcasses between 50 and $120 \mathrm{~kg}$. The real-time ultrasonograph technology is accurate to estimate the Longissimus muscle area and backfat tickness in live animal.
\end{abstract}

Key Words: backfat thickness, lean meat yield, loin eye area, meat cuts, multiple and simple equations

\section{Introdução}

O Método Brasileiro de Classificação de Carcaças de Suínos (MBCC) consiste em medidas de espessura de toucinho, de área de olho de lombo, de comprimento de carcaça, de rendimentos de cortes cárneos e de rendimento de carcaça, obtidas na meia carcaça esquerda (ASSOCIAÇÃO BRASILEIRA DE CRIADORES DE SUÍNOS - ABCS, 1973). Entretanto, apesar de ser preciso, não tem sido utilizado pela indústrias de carne e derivados, no Brasil.

Provavelmente, as dificuldades e a demora na obtenção das informações de carcaças de suínos pelo

\footnotetext{
1 Parte da tese apresentada à UFV para obtenção do título de "Doctor Scientiae."

2Professor da PUC - Uruguaiana, RS. E.mail: wmd@pucrs.campus2.br

3 Professor do DZO/UFV.

${ }^{4}$ Zootecnista.
} 
MBCC sejam as causas da não-adoção do método pelos frigoríficos e abatedouros de suínos.

A partir de meados da década de 80 , as indústrias frigoríficas (em especial, as do Centro-Sul), no Brasil, passaram a adotar processos e técnicas de classificação de carcaças, visando não só premiar os suinocultores que produzissem suínos com carcaças de melhor qualidade, como também melhorar o seu próprio rendimento industrial.

As indústrias suinícolas estão procurando abater animais mais pesados, buscando reduzir custos e aumentar a escala de produção. A evolução genética experimentada pela maioria das linhagens comerciais disponíveis hoje no mercado, pode contribuir para que os animais sejam abatidos mais jovens e com maior peso.

Tem-se verificado que a deposição de gordura e proteína nas carcaças é linearmente relacionada com o aumento de peso e idade, havendo mudança na proporção relativa destes dois componentes, de modo que a gordura se deposita mais tardiamente que a proteína e, por isso, talvez, a diminuição da eficiência alimentar com o aumento de peso seja atribuída primeiramente ao aumento dos gastos energéticos para mantença, e não ao acréscimo da deposição de gordura (ROBINSON, 1976).

O estudo de meios eficazes de estimar composição corporal in vivo no Brasil ainda é incipiente, porém em países desenvolvidos já é uma realidade. Existem várias técnicas para avaliação e classificação de carcaças de suínos; entre elas podem-se destacar aquelas com uso de aparelhos ópticos durante o processo de abate e as técnicas com uso de ultra-sonografia.

Provavelmente, as técnicas com uso de ultrasonografia em tempo real não estejam sendo usadas, devido à falta de informações e validações de dados de carcaças obtidos no Brasil.

Assim, verifica-se ser necessário determinar parâmetros precisos e acurados para a estimativa de rendimentos de cortes comerciais e de carne magra na carcaça de suínos, visando-se estimar AOL e ET, utilizando-se a técnica de ultra-sonografia em tempo real.

\section{Material e Métodos}

Foram selecionadas 48 fêmeas suínas da linhagem Camborough 22, com peso médio inicial de $25,53 \mathrm{~kg}$ e idade média de 62 dias.
Os animais foram alojados nas instalações da granja multiplicadora da Cooperativa Mista General Osório Ltda., em XV de Novembro, RS.

Os animais foram alimentados à vontade com rações convencionais distribuídas para os cooperados da Cotribá.

Antes das pesagens, os animais foram conduzidos à uma baia de passagem com catre elevatório, construído especialmente para a verificação das medidas ultra-sônicas. Esse equipamento permitiu suspender o animal pelo peito e pela barriga, imobilizando-o completamente, para facilitar a tomada perfeita das imagens.

Para a realização das medidas ultra-sônicas, utilizou-se um conjunto de equipamentos constituído de: uma ecocâmera ALOKA SSD 500, uma probe de $11,5 \mathrm{~cm}$ e 3,5 MHz, duas guias acústicas ou standoff, para medidas longitudinais e transversais, e um software AUSKey-4 System for Windows 5.0, acoplado a um notebook, com cartão PCMCIA.

As medidas ultra-sônicas foram coletadas após a contenção dos animais, utilizando-se primeiramente a guia transversal para tomada da área de olho de lombo e, em seguida, uma medida longitudinal para a espessura de toucinho e profundidade de músculo, para cada animal. A primeira medida foi coletada transversalmente entre a décima e a décima primeira costelas, por meio de uma guia acústica de polivinil, que se ajustou perfeitamente à curvatura dessa região do animal. A segunda medida foi tomada com uma guia acústica reta, que permitiu perfeito ajustamento do transdutor na área compreendida entre a décima e a última costelas dos suínos, a $5 \mathrm{~cm}$ abaixo da linha média.

Para o cálculo do rendimento de carne magra, área de olho de lombo e espessura de toucinho, utilizou-se o software AUSKey System V-5.0, for windows, desenvolvido por LIU (1997), cujos resultados geraram equações de predição que levam em conta o peso do animal, a profundidade de músculo e a espessura de toucinho, como variáveis.

Para a visualização das imagens, utilizou-se o programa Image Wizard, versão 3.3, da seguinte forma: 1) cada imagem foi identificada com o número do animal, a data e o respectivo peso; 2) após a abertura da imagem, visualizava-se na tela do computador uma planilha do Excel, com uma coluna de identificação do animal, uma com o peso e outras duas colunas, uma para a espessura de toucinho e outra para a área de olho de lombo, que foram traçadas manualmente com o uso do mouse do com- 
putador; e 3) após a identificação destas três variáveis, o software forneceu a estimativa in vivo de carne magra na carcaça.

Os animais foram abatidos no frigorífico da COOPERJACUÍ, Central de Cooperativas do Alto Jacuí, aos 50, 60, 70, 80, 90, 100 e 120 kg após transporte, com duração de 2,5 horas, em média. No descarregamento, os animais foram identificados por meio de quatro tatuagens em diferentes partes do corpo e cada um, pesado e alojado nas baias de espera. O abate ocorreu após jejum de ração de 24 horas.

Após o abate, as carcaças foram acompanhadas na linha de abate, da seguinte forma: primeiramente retiraram-se as vísceras brancas e vermelhas, colocando-as em bandejas separadas e numeradas; logo em seguida, desviaram-se os animais para a retirada de cabeça, patas, rabo e unto, para posterior pesagem de todas essas partes, obtendo-se assim o peso da carcaça quente. Em seguida, procedeu-se às medições para estimativas de rendimentos feitas pela indústria, por meio de equipamento óptico Hennessy. Com este equipamento, estimaram-se espessura de toucinho (ETOP) e profundidade de músculo (PMOP) a $5 \mathrm{~cm}$ abaixo da linha média, na altura da décima costela. Após esses procedimentos, as carcaças foram levadas para a câmara fria.

Após o período de resfriamento mínimo de 24 e máximo 72 horas, à temperatura de $5^{\circ} \mathrm{C}$, foi realizada a dissecação das meias-carcaças esquerdas, procedendo-se da seguinte forma: 1) medida da temperatura da carcaça nos músculos do pernil, do lombo e da paleta, calculando-se a média; 2) as carcaças foram pesadas em balança eletrônica, retiradas dos ganchos e serradas na linha mediana, por uma serra de fita; 3) a meia-carcaça esquerda foi posteriormente dividida em partes, paleta, pernil, copa, carré e barriga, de acordo com o método adotado pela indústria; 4) pesou-se cada parte em balança digital com precisão de $5 \mathrm{~g} ; 5)$ separou-se a pele da gordura subcutânea; 6) retiraram-se os ossos; 7) separaram-se os músculos, removendo-se o máximo da gordura intermuscular; e 8) as fáceas e as aponeuroses dos músculo foram deixadas nos mesmos, separando-se também os gânglios.

As porções de músculo, gordura, pele, ossos e gânglios foram colocadas em sacos plásticos e pesadas em balança digital, para calcular os rendimentos de carne magra, a porcentagem de gordura e a porcentagem de ossos, além dos diversos cortes comerciais.
Analisaram-se os dados por intermédio de regressões lineares simples e múltiplas, conforme o pacote computacional SAEG, Sistema de Análises Estatísticas e Genéticas (UNIVERSIDADE FEDERAL DE VIÇOSA - UFV, 1998).

\section{Resultados e Discussão}

Na Tabela 1, estão apresentados os pesos e as porcentagens de cortes em relação ao peso dos suínos vivos.

O primeiro corte em quantidade de carne na carcaça foi o pernil, com valores de 29,2 a $30,8 \%$ do total de músculo na carcaça. O corte da paleta representou de 21,2 a $23 \%$ do total de músculos na carcaça, correspondendo ao segundo corte em importância do ponto de vista industrial. O carré foi o terceiro corte em quantidade de carne na carcaça, representando de 21,0 a 22,6\% do total de músculo. Percentualmente, a barriga ficou em quarto lugar em quantidade de músculo, com 16,1 a 18,9\%, contra 7,7 a 9,0\% da copa, porém é conveniente ressaltar a dificuldade de se dissecarem estes dois cortes, devido à grande quantidade de gordura entremeada aos músculos.

Na Tabela 2, estão apresentadas as equações de predição para os diferentes tecidos das carcaças de suínos e, a partir da visualização dos dados, verificase que as equações de regressão para quantidade de músculo, gordura e ossos na carcaça apresentaram valores de $\mathrm{R}^{2}$ superiores a 0,99 , com desvio-padrão residual entre 0,77 e 2,14 , enquanto a equação para quantidade de pele na carcaça o $\mathrm{R}^{2}$ foi de 0,88 e o desvio-padrão residual, de 0,34 .

A dissecação de carcaças realizada em diferentes pesos corporais permitiu a coleta de dados, os quais foram utilizados para a construção de equações de predição para crescimento de tecidos. A separação dos cortes comerciais de acordo com os critérios utilizados pela indústria facilitou o serviço de dissecação, além de possibilitar uma interpretação mais realista dos dados de rendimento com aqueles buscados pelo mercado.

Verificou-se, portanto, que o desvio-padrão residual para estas características foi enquadrado dentro do limite máximo fixado pela Comunidade Européia, na definição de equações para se estimar o rendimento de carne em suínos (DIESTRE et al., 1989; HULSEGGUE et al., 1994).

$\mathrm{Na}$ Tabela 3, são apresentadas as equações de predição para os diferentes cortes comerciais de 
carcaças de suínos. Verificou-se que o $\mathrm{R}^{2}$ para todos os cortes foi de 0,99 , tendo o desvio-padrão residual variado entre 0,39 e 0,77 , cujos valores estão abaixo do máximo fixado pala Comunidade Européia, que é de 2,5. Estes resultados, associados aos das equações de predições das quantidades de tecidos, podem dar sustentação à hipótese de que é possível estimar os rendimentos de cortes comerciais a partir de informações obtidas pela dissecação de carcaças.

$\mathrm{Na}$ Tabela 4, são mostradas as estimativas de rendimento de carne magra para os cortes de pernil, paleta, carré, copa e barriga, cujas equações mostraram $\mathrm{R}^{2}$ de 0,$99 ; 0,99 ; 0,99 ; 0,99$; e 0,97 e desviopadrão residual de 0,$77 ; 0,59 ; 0,55 ; 0,27$; e 0,57 , respectivamente. Esses resultados são maiores que os obtidos por BRONDUM et al. (1998), os quais, trabalhando com outros preditores de carcaça, encontraram valores de $\mathrm{R}^{2}$ de 0,65 a 0,85 e DPR de 1,70 a 2,44 . Isso pode ser indicativo de que as quantidades de músculo no pernil, na paleta, no carré, na copa e barriga, estimadas a partir da dissecação das carcaças, foram melhores preditores de carcaça que os usados por BRONDUM et al. (1998).

$\mathrm{Na}$ Tabela 5, são apresentados os dados de rendimento de músculo e gordura dos diferentes cortes comerciais das carcaças de suínos, verificando-se que o corte do pernil apresentou a maior relação carne: gordura, 4,0 a 5,4 partes de carne para 1,0 parte de gordura. A paleta mostrou relação carne: gordura de 1,5 a 2,3 e a copa, de 5,8 a 6,6 e, apesar de ser um corte com muita gordura intermuscular, apresentou maior proporção de carne que o pernil. O carré apresentou relação carne:gordura de 2,3 a 3,5 e a barriga foi o corte com a menor relação carne:gordura, de 1,5 a 2,4, evidenciando a grande dificuldade de dissecar essa parte da carcaça dos suínos, devido à grande quantidade de gordura intermuscular.

Elaboraram-se também equações de predição para estimar a quantidade de gordura presente nos diferentes cortes comerciais de carcaças de suínos, cujos resultados são apresentados na Tabela 6, na qual se pode verificar que o ajuste de $\mathrm{R}^{2}$ variou de 0,95 a 0,99 , para gordura no pernil, na paleta, na copa, no carré e na barriga, apresentando também baixos desvios-padrão residuais, entre 0,09 e 0,78 .

As equações para estimar o rendimento de carne magra para os diferentes cortes comerciais de carcaças de suínos, apresentadas na Tabela 6, demonstraram resultados superiores aos encontrados por WAGNER et al. (1999), que, trabalhando com dife- 
Rev. bras. zootec.

Tabela 2 - Equações de predição, para os diferentes tecidos das carcaças de suínos

Table 2 - Prediction equations for the different swines carcass tissues

\begin{tabular}{|c|c|c|c|}
\hline $\begin{array}{l}\text { Componente } \\
\text { Component }\end{array}$ & $\begin{array}{l}\text { Regressão } \\
\text { Regression }\end{array}$ & $\mathrm{R}^{2}$ & DPR \\
\hline Quantidade de músculo na carcaça & $\hat{\mathrm{Y}}=-2,7532+0,4628 \mathrm{PV}(L W)$ & 0,99 & 1,75 \\
\hline $\begin{array}{l}\text { Quantidade de gordura na carcaça } \\
\text { Fat amount in the carcass }\end{array}$ & $\hat{\mathrm{Y}}=-4,0147+0,2217 \mathrm{PV}(L W)$ & 0,99 & 2,14 \\
\hline $\begin{array}{l}\text { Quantidade de ossos na carcaça } \\
\text { Bones amount in the carcass }\end{array}$ & $\hat{\mathrm{Y}}=-1,0189+0,1245 \mathrm{PV}(L W)$ & 0,99 & 0,77 \\
\hline $\begin{array}{l}\text { Quantidade de pele na carcaça } \\
\text { Skin amount in the carcass }\end{array}$ & $\hat{\mathrm{Y}}=1,5925+0,0211 \mathrm{PV}(L W)$ & 0,88 & 0,34 \\
\hline
\end{tabular}

PV (Peso vivo).

$R^{2}$ (Coeficiente de determinação).

DPR (Desvio-padrão residual).

LW (Live weight).

R2 (Coefficient of determination).

RSD (Residual standard deviation).

Tabela 3 - Equações de predição para os diferentes cortes comerciais das carcaças de suínos

Table 3 - Prediction equations for the different commercial cuts of swines carcass

\begin{tabular}{|c|c|c|c|}
\hline $\begin{array}{l}\text { Componente } \\
\text { Component }\end{array}$ & $\begin{array}{l}\text { Regressão } \\
\text { Regression }\end{array}$ & $\mathrm{R}^{2}$ & DPR \\
\hline $\begin{array}{l}\text { Peso do corte do pernil } \\
\text { Ham cut weight }\end{array}$ & $\hat{\mathrm{Y}}=-0,3977+0,1948 \mathrm{PV}(L W)$ & 0,99 & 0,77 \\
\hline $\begin{array}{l}\text { Peso do corte de paleta } \\
\text { Shoulder cut weight }\end{array}$ & $\hat{\mathrm{Y}}=0,0257+0,1828 \mathrm{PV}(L W)$ & 0,99 & 0,59 \\
\hline $\begin{array}{l}\text { Peso do corte do carré } \\
\text { Carré cut weight }\end{array}$ & $\hat{\mathrm{Y}}=-2,6083+0,1099 \mathrm{PV}(L W)$ & 0,99 & 0,55 \\
\hline $\begin{array}{l}\text { Peso do corte da copa } \\
\text { Loin copa cut weight }\end{array}$ & $\hat{\mathrm{Y}}=0,2602+0,0462 \mathrm{PV}(L W)$ & 0,99 & 0,39 \\
\hline $\begin{array}{l}\text { Peso do corte da barriga } \\
\text { Bellycutweight }\end{array}$ & $\hat{\mathrm{Y}}=-1,9230+0,1704 \mathrm{PV}(L W)$ & 0,99 & 0,59 \\
\hline $\begin{array}{ll}\mathrm{PV} & \text { (Peso vivo). } \\
\mathrm{R}^{2} & \text { (Coeficiente de determinação). } \\
\mathrm{DPR} & \text { (Desvio-padrão residual). } \\
L W & \text { (Live weight). } \\
R 2 & \text { (Coefficient of determination). } \\
R S D & \text { (Residual standard deviation). }\end{array}$ & & & \\
\hline
\end{tabular}

Tabela 4 - Equações de predição para estimar o rendimento de carne magra para os diferentes cortes comerciais das carcaças de suínos

Table 4 - Prediction equations to estimate the lean meat yield for the different commercial cuts of swines carcass

\begin{tabular}{|c|c|c|c|}
\hline $\begin{array}{l}\text { Componente } \\
\text { Component }\end{array}$ & $\begin{array}{l}\text { Regressão } \\
\text { Regression }\end{array}$ & $\mathrm{R}^{2}$ & DPR \\
\hline $\begin{array}{l}\text { Quantidade de músculo do pernil } \\
\text { Ham muscle amount }\end{array}$ & $\hat{\mathrm{Y}}=-0,5984+0,1351 \mathrm{PV}(L W)$ & 0,99 & 0,77 \\
\hline $\begin{array}{l}\text { Quantidade de músculo da paleta } \\
\text { Shoulder muscle amount }\end{array}$ & $\hat{\mathrm{Y}}=-0,1140+0,9634 \mathrm{PV}(L W)$ & 0,99 & 0,59 \\
\hline $\begin{array}{l}\text { Quantidade de músculo do carré } \\
\text { Carré muscle amount }\end{array}$ & $\hat{\mathrm{Y}}=-1,2492+0,1099 \mathrm{PV}(L W)$ & 0,99 & 0,55 \\
\hline $\begin{array}{l}\text { Quantidade de músculo da copa } \\
\text { Loin copa muscle amount }\end{array}$ & $\hat{\mathrm{Y}}=0,2184+0,0324 \mathrm{PV}(L W)$ & 0,99 & 0,27 \\
\hline $\begin{array}{l}\text { Quantidade de músculo da barriga } \\
\text { Belly muscle amount }\end{array}$ & $\hat{\mathrm{Y}}=-1,0100+0,0888 \mathrm{PV}(L W)$ & 0,97 & 0,57 \\
\hline
\end{tabular}

\footnotetext{
PV (Peso vivo).

$R^{2}$ (Coeficiente de determinação).

DPR (Desvio-padrão residual).

LW (Live weight).

$R 2$ (Coefficient of determination).

$R S D$ (Residual standard deviation).
} 
DUTRA JR. et al.

Tabela 5 - Quantidade de músculo e gordura nos cortes comerciais de carcaças de suínos Table 5 - Fat and muscle amounts in the commercial cuts of swines carcass

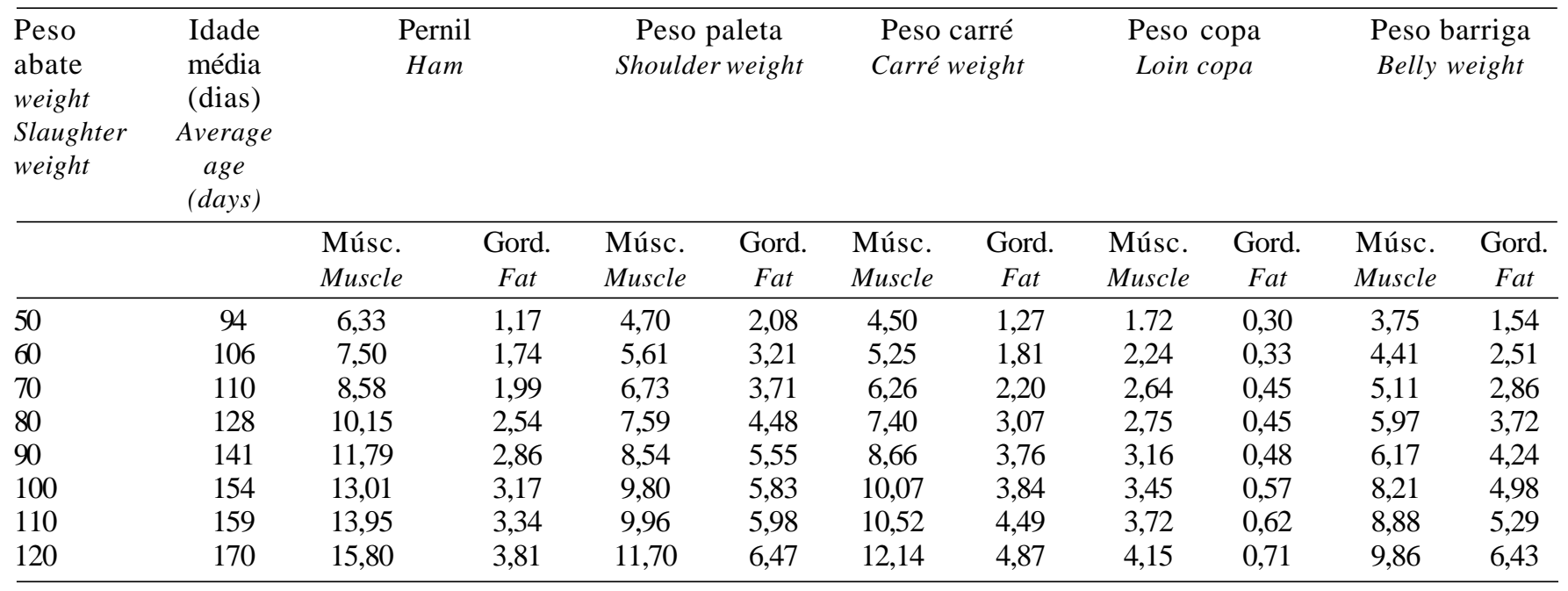

Músc. (Muscle).

Gord. (Fat).

rentes modelos, como o linear, quadrático, alométrico e não-linear, encontraram valores de $\mathrm{R}^{2}$ não-superiores a 0,959 e desvio-padrão residual entre 2,79 e 3,15 , para a estimação de músculo livre de gordura.

Na Tabela 7, são apresentados os dados de área de olho de lombo, espessura de toucinho e profundidade de músculo, obtidos por intermédio dos diferentes métodos de avaliação, para AOL. Observou-se que, em geral, os valores medidos pela ultra-sonografia em tempo real foram menores que aqueles medidos na carcaça dissecada, o que provavelmente pode ser explicado pelo relaxamento normal da musculatura após o abate e também pela influência do processo de corte e seccionamento do carré, para a tomada da medida. Os valores de ET foram bastante semelhantes, porém maiores para as medidas ultrasônicas, provavelmente devido ao mesmo efeito, uma vez que o animal vivo apresenta tônus corporal fazendo com que adquira conformação diferente daquela experimentada pela carcaça, após o processo de abate, pendura, resfriamento e posterior corte da carcaça.

Os ajustes de equações lineares simples e múltiplas, para estimativa de características de carcaças, a partir dos dados obtidos com as diferentes medidas feitas nas carcaças, tanto em animais vivos, como diretamente nas carcaças, podem ser visualizados na

Tabela 6 - Equações para estimar a quantidade de gordura para os diferentes cortes comerciais de carcaças de suínos

Table 6 - Equations to estimate the fat amount for the different commercial cuts of swines carcass

\begin{tabular}{|c|c|c|c|}
\hline $\begin{array}{l}\text { Componente } \\
\text { Component }\end{array}$ & $\begin{array}{l}\text { Regressão } \\
\text { Regression }\end{array}$ & $\mathrm{R}^{2}$ & DPR \\
\hline $\begin{array}{l}\text { Quantidade de gordura do pernil } \\
\text { Ham fat amount }\end{array}$ & $\hat{\mathrm{Y}}=-0,4910+0,0361 \mathrm{PV}(L W)$ & 0,99 & 0,40 \\
\hline $\begin{array}{l}\text { Quantidade de gordura da paleta } \\
\text { Shoulder fat amount }\end{array}$ & $\hat{\mathrm{Y}}=-0,6035+0,0619 \mathrm{PV}(L W)$ & 0,95 & 0,78 \\
\hline $\begin{array}{l}\text { Quantidade de gordura do carré } \\
\text { Carré fat amount }\end{array}$ & $\hat{\mathrm{Y}}=-1,1308+0,0526 \mathrm{PV}(L W)$ & 0,98 & 0,69 \\
\hline $\begin{array}{l}\text { Quantidade de gordura da copa } \\
\text { Loin copa fat amount }\end{array}$ & $\hat{\mathrm{Y}}=0,0084+0,0057 \mathrm{PV}(L W)$ & 0,96 & 0,09 \\
\hline $\begin{array}{l}\text { Quantidade de gordura da barriga } \\
\text { Belly fat amount }\end{array}$ & $\hat{\mathrm{Y}}=-1,6200+0,0654 \mathrm{PV}(L W)$ & 0,99 & 0,61 \\
\hline $\begin{array}{ll}\mathrm{PV} & \text { (Peso vivo). } \\
\mathrm{R}^{2} & \text { (Coeficiente de determinação). } \\
\mathrm{DPR} & \text { (Desvio-padrão residual). } \\
L W & \text { (Live weight). } \\
R 2 & \text { (Coefficient of determination). } \\
R S D & \text { (Residual standard deviation). }\end{array}$ & & & \\
\hline
\end{tabular}


Rev. bras. zootec.

Tabela 7 - Valores observados para as características carcaças de suínos, por meio de três técnicas Table 7 - Values observed for the swines carcass traits, by means of three techniques

\begin{tabular}{|c|c|c|c|c|c|c|c|}
\hline \multirow{2}{*}{$\begin{array}{l}\text { Peso abate } \\
(\mathrm{kg}) \\
\text { Slaughter } \\
\text { weight }\end{array}$} & \multirow{2}{*}{$\begin{array}{l}\text { Idade média } \\
\text { (dias) } \\
\text { Average age } \\
\text { (days) }\end{array}$} & \multicolumn{2}{|c|}{$\begin{array}{c}\mathrm{AOL} \\
\text { Loin eye area }\end{array}$} & \multicolumn{3}{|c|}{$\begin{array}{c}\text { ET } \\
\text { Backfat thickness }\end{array}$} & \multirow{2}{*}{$\begin{array}{c}\text { PM } \\
\text { Muscle depth } \\
\text { Óptico } \\
\text { (mm) } \\
\text { Optical }\end{array}$} \\
\hline & & $\begin{array}{l}\text { Ultra-som } \\
\left(\mathrm{cm}^{2}\right) \\
\text { Ultra-sound }\end{array}$ & $\begin{array}{c}\text { Carcaça } \\
\left(\mathrm{cm}^{2}\right) \\
\text { Carcass }\end{array}$ & $\begin{array}{l}\text { Ultra-som } \\
(\mathrm{mm}) \\
\text { Ultra-sound }\end{array}$ & $\begin{array}{c}\text { Carcaça } \\
(\mathrm{mm}) \\
\text { Carcass }\end{array}$ & $\begin{array}{l}\text { Óptico } \\
\text { (mm) } \\
\text { Optical }\end{array}$ & \\
\hline 50 & 94 & 22,77 & 29,73 & 7,55 & 6,83 & 7,00 & 42,73 \\
\hline 60 & 106 & 26,56 & 30,59 & 9,75 & 9,42 & 9,58 & 42,46 \\
\hline 70 & 110 & 32,60 & 34,57 & 12,40 & 9,00 & 9,20 & 46,40 \\
\hline 80 & 128 & 37,54 & 38,71 & 14,77 & 11,25 & 12,28 & 53,77 \\
\hline 90 & 141 & 43,89 & 41,83 & 16,28 & 14,33 & 14,13 & 53,63 \\
\hline 100 & 154 & 44,21 & 47,11 & 16,10 & 13,08 & 14,02 & 57,10 \\
\hline 110 & 159 & 44,17 & 48,72 & 16,40 & 14,17 & 14,07 & 52,36 \\
\hline 120 & 170 & 49,04 & 55,49 & 16,40 & 14,42 & 13,82 & 54,90 \\
\hline
\end{tabular}

AOL (Área de olho de lombo).

ET (Espessura de toucinho).

PM (Profundidade de músculo).

AOL (Loin eye area).

ET (Backfat thickness).

PM (Muscle depth).

Tabela 8 , na qual se constata que a equação para estimar a espessura de toucinho medida diretamente na carcaça dissecada apresentou menor valor de $\mathrm{R}^{2}$ que a equação para se estimar a espessura de toucinho medida indiretamente via ultra-som; os valores de desvio-padrão residual verificados com o ultra-som foram menores que os de desvio-padrão residual obtidos na dissecação da carcaça com aparelho óptico; e o valor de $\mathrm{R}^{2}$ para espessura de toucinho com ultrasom foi menor que com aparelho óptico.

$\mathrm{O}$ menor valor de $\mathrm{R}^{2}$ obtido nas equações da espessura de toucinho in vivo, talvez, possa ser explicado pelas grandes mudanças fisiológicas que ocorrem na carcaça, no post-mortem, que podem

Tabela 8 - Ajuste de equações para estimação de características de carcaças de suínos

Table 8 - Equations fitted to swines carcass traits estimate

\begin{tabular}{|c|c|c|c|}
\hline $\begin{array}{l}\text { Componente } \\
\text { Component }\end{array}$ & $\begin{array}{l}\text { Regressão } \\
\text { Regression }\end{array}$ & $\mathrm{R}^{2}$ & DPR \\
\hline $\begin{array}{l}\text { AOL medida por ultra-som } \\
\text { LEA measured by ultra-sound }\end{array}$ & $\hat{\mathrm{Y}}=-19,696+1,022-0,0038 \mathrm{PV}(L W)$ & 0,97 & 3,07 \\
\hline $\begin{array}{l}\text { AOL medida na carcaça dissecada } \\
\text { LEA measured by dissected carcass }\end{array}$ & $\hat{\mathrm{Y}}=9,2979+0,3711 \mathrm{PV}(L W)$ & 0,98 & 4,04 \\
\hline $\begin{array}{l}\text { ET medida por ultra-som } \\
\text { BT measured by ultra-sound }\end{array}$ & $\hat{\mathrm{Y}}=-15,9279-0,0028+0,6034 \mathrm{PV}(L W)$ & 0,99 & 2,39 \\
\hline $\begin{array}{l}\text { ET medida na carcaça dissecada } \\
\text { BT measured by dissected carcass }\end{array}$ & $\hat{\mathrm{Y}}=2,2361+0,1097 \mathrm{PV}(L W)$ & 0,86 & 2,91 \\
\hline $\begin{array}{l}\text { ET medida por aparelho óptico } \\
\text { BT measured by optical equipment }\end{array}$ & $\hat{\mathrm{Y}}=3,0121+0,1029 \mathrm{PV}(L W)$ & 0,82 & 3,13 \\
\hline $\begin{array}{l}\text { PM medido por aparelho óptico } \\
\text { MD measured by optical equipment }\end{array}$ & $\hat{\mathrm{Y}}=5,9482-0,0041+0,8989 \mathrm{PV}(L W)$ & 0,85 & 4,17 \\
\hline $\begin{array}{ll}\mathrm{PV} & \text { (Peso vivo). } \\
\mathrm{R}^{2} & \text { (Coeficiente de determinação). } \\
\mathrm{DPR} & \text { (Desvio-padrão residual). } \\
\mathrm{AOL} & \text { (Área de olho de lombo). } \\
\mathrm{ET} & \text { (Espessura de toucinho). } \\
\mathrm{PM} & \text { (Profundidade de músculo). } \\
L W & \text { (Live weight). } \\
R^{2} & \text { (Coefficient of determination). } \\
R S D & \text { (Residual standard deviation). } \\
L E A & \text { (Loin eye area). } \\
B T & \text { (Backfat thickness). } \\
M D & \text { (Muscle depth). }\end{array}$ & & & \\
\hline
\end{tabular}


interferir nos resultados da medida de espessura de toucinho realizada nas carcaças após o resfriamento.

Os menores valores de desvio-padrão residual, obtidos com a técnica de ultra-sonografia em tempo real, podem ser indicativo de que esta técnica é bastante acurada para estimar ET, nos diferentes pesos corporais avaliados. Estes dados foram superiores àqueles obtidos por SATHER et al. (1996), os quais encontraram valores de $\mathrm{R}^{2}$ de 0,72 para estimativas de espessura de toucinho, via ultra-som (CS3000 ), e de 0,68 para estimativas realizadas por meio do aparelho óptico (Hennessy).

Quanto à profundidade de músculo, medida por intermédio do aparelho óptico, verificaram-se valores de $\mathrm{R}^{2}$ de 0,85 e desvio-padrão residual de 4,17 , os quais estão abaixo das demais estimativas. É importante destacar que este tem sido o mecanismo de estimação de rendimento de carne magra adotado pela indústria brasileira.

Os valores de desvio-padrão residual obtidos nesta pesquisa foram maiores àqueles obtidos por IRGANG et al. (1998), os quais encontraram valores entre 1,24 e 2,61, porém, vale lembrar que esses pesquisadores utilizaram uma combinação das duas medias, ou seja, espessura de toucinho e profundidade de músculo e encontraram valores de R2 entre 70,7 e 95,5, sendo que os maiores valores de R2 e os menores desviospadrão residuais foram obtidos com combinações de medidas em vários locais da mesma carcaça.

\section{Conclusões}

A partir dos resultados combinados obtidos neste estudo, é possível inferir que a técnica de ultrasonografia em tempo real pode ser eficiente na estimativa da área de olho de lombo e da espessura de toucinho de suínos in vivo, uma vez que os resultados obtidos mostraram-se consistentes e precisos e de maior acuracidade que os obtidos por outras vias.

As equações obtidas por regressões lineares simples e múltiplas ajustam equações precisas para estimar rendimento de cortes comerciais e de carne magra nas carcaças de suínos.

A técnica de ultra-sonografia em tempo real é acurada para se estimarem a área de olho de lombo e a espessura de toucinho de suínos in vivo.

\section{Referências Bibliográficas}

ASSOCIAÇÃO BRASILEIRA DE CRIADORES DE SUÍNOS - ABCS. 1973. Método brasileiro de classificação de carcaças. Estrela, RS.

BRONDUM, J., EGEBO, M., AGERSKOV, C. et al. 1998. Online pork carcass grading with the Autofom ultrasound system, J. Anim. Sci., 76(7):1859-1868.

DIESTRE, A., GISPERT, M., OLIVER, M.A. 1989. The evaluation of automatic probes in Spain for the new scheme for pig carcass grading according to the $\mathrm{E} C$ regulations. Anim. Prod., 48(2):443-448.

HULSEGGE, B., STERRENBURG, P., MERKUS, G.S.M. 1994. Prediction of lean meat proportion in pig carcasses and in the major cuts from multiple measurements made with the Hennessey Grading Probe. Anim. Prod. 59(1):119-123.

IRGANG, R., GUIDONI, A.L., BERLITZ, D., CORSO, C.M. 1998. Medidas de espessura de toucinho e de profundidade de músculo para estimar rendimento de carne magra em carcaças de suínos, R. Bras. Zootec., 27(5):928-935.

LIU, Y. 1997. AUSKEY FOR WINDOWS VERSION 5.00, ANIMAL ULTRASOUND SERVICES INC, 95 Brown Road Room 248, Ithaca, NY, Users Manual, Copyright. 192p.

ROBINSON, O.W. 1976. Growth patterns in swine. J. Anim. Sci., 42(4):1024-1035.

SATHER, A.P., BAILEY, D.R.C., JONES, S.D.M. 1996. Realtime ultrasound image analysis for the estimation of carcass yield an pork quality. Can. J. Anim. Sci. 76(1):55-62.

WAGNER, J.R., SCHINCKEL, A.P., CHEN, W. et al. 1999. Analysis of body composition changes of swine during growth and development. J. Anim. Sci., 77:1442-1466.

UNIVERSIDADE FEDERAL DE VIÇOSA - UFV. 1998. SAEG - Sistema de análises estatísticas e genéticas. Versão 7.1. Viçosa, MG. 150p. (Manual do usuário).
Recebido em: 27/09/00

Aceito em: 15/05/01 